\title{
KONFORMITAS TEMAN SEBAYA DALAM PERSPEKTIF MULTIKULTURAL
}

\author{
Ranni Rahmayanthi $\mathrm{Z}^{1}$
}

\begin{abstract}
The aim of this study was to determine the conformity profile peers based on multiculture perspective. Participants in this study weres 76 students senior hig school consist of 32 boys student and 44 girls students. This research approach using quantitative approach, types of research using a cross sectional survey. The instruments used was a scale conformity peers. Data were analyzed using analysis Mann-Whitney U with a score of 702,5 and a significance probability value of 0.414 . Because the probability of significance $0.987>0.05$, the results showed that there was no difference conformity peers in the boys student and girls student.
\end{abstract}

Keywords: Adolesence, Conformity, Multiculture.

JOMSIGN: Journal of Multicultural Studies in Guidance and Counseling

Website : http://ejournal.upi.edu/index.php/JOMSIGN

Permalink: http://ejournal.upi.edu/index.php/JOMSIGN/article/view/6052

How to cite (APA): Rahmayanthi Z, R. (2017). Konformitas teman sebaya dalam perspektif multikultural. JOMSIGN Journal of Multicultural Studies in Guidance and Counseling, 1(1), 71-82.

This is an open access article distributed under the terms of the Creative Commons Attribution 4.0 International License, which permits unrestricted use, distribution, and reproduction in any medium, provided the original work is properly cited.

\section{PENDAHULUAN}

Tahap perkembangan remaja merupakan masa transisi dari kanak-kanak menuju dewasa. Dalam perkembangan sosial remaja ada dua macam gerak yaitu memisahkan diri dari orang tua dan yang lain adalah menuju teman sebayanya. Hal ini merupakan reaksi terhadap status anak muda (Mönks \&Haditono, 2004). Dalam masa remaja, remaja berusaha untuk melepaskan diri dari orang tua dengan maksud untuk menemukan dirinya, proses ini dinamai proses mencari identitas ego (Erikson, 1968).

Setiap tahap perkembangan memiliki tugas-tugas perkembangan masingmasing, begitu pula tahap perkembangan remaja. salah satu tugas perkembangan remaja adalah berhubungan dengan penyesuaian sosial. Remaja

\footnotetext{
${ }^{1}$ Universitas Lampung, Indonesia; rannirahmayanthi@yahoo.com.
} 
harus menyesuaikan diri dengan lawan jenis dalam hubungan yang sebelumnya belum pernah ada dan harus menyesuaikan dengan orang dewasa diluar lingkungan keluarga dan sekolah. Selain itu, yang tersulit dan tidak kalah penting adalah penyesuaian diri dengan meningkatnya pengaruh kelompok sebaya, perubahan dalam perilaku sosial, pengelompokan sosial yang baru, nilai-nilai baru dalam dukungan dan penolakan sosial.

Remaja berusaha untuk mencapai originalitas sekaligus menunjukkan pertentangan terhadap orang dewasa dan solidaritas teman-teman sebaya. Remaja cendrung banyak menghabiskan waktu bersama teman sebaya, membentuk kelompok dan melepaskan dirinya dari pengaruh orang dewasa. Seorang remaja mengubah perilakunya atau sikap untuk lebih menyerupai perilaku atau sikap dari suatu kelompok disebut dengan konformitas (Cialdini \& Goldstein, 2004).

Remaja melakukan konformitas kepada teman sebaya tidak hanya perilaku yang ditiru melainkan dalam mengambil keputusan, banyak remaja yang kesulitan memutuskan sesuatu, namun pertimbangan dari teman sebaya yang biasanya didengarkan oleh remaja dari pada orang tua (Cash, 2002). Remaja lebih merasa senang membentuk kelompok-kelompok, seperti komunitas-komunitas tertentu yang dibentuk berdasarkan kesamaan hobi seperti komunitas anak motor, komunitas graffiti, komunitas pecinta kucing dll sehingga mereka merasa senasib.

Konformitas adalah merubah tindakan atau perilaku yang disebabkan oleh tekanan dari sesuatu atau kelompok tertentu. (Song, 2012). Konformitas biasanya dilakukan oleh peserta didik usia remaja terhadap kelompok teman sebaya. Remaja masih memiliki emosi yang mudah berubah-ubah sehingga membuat remaja mudah mengambil keputusan yang bertentangan dengan norma-norma yang ada agar diterima di suatu kelompok-kelompok tertentu. Konformitas terjadi ketika seseorang merubah perilaku atau sikap agar menyerupai perilaku atau sikap suatu kelompok tertentu (Cialdini \& Goldstein, 2004).

Konformitas diartikan sebagai perubahan perilaku individu untuk mengikuti perilaku orang lain agar diterima disuatu kelompok tertentu (Cialdini \& Goldstein, 2004; Myers, 2010; Song, 2012; Tolley, 2013). Faktor yang mempengaruhi konformitas diungkapkan oleh Song (2012) konformitas terbentuk karena adanya dorongan dari beberapa faktor yaitu besarnya kelompok dan adanya kesepakatan. Besarnya kelompok mempengaruhinya 
remaja berperilaku konform, semakin besar suatu kelompok yang ada disekitarnya akan semakin besar pengaruhnya kepada seseorang individu. Dan apabila di dalam kelompok tersebut telah terbentuk satu keputusan bersama, baik secara sukarela maupun terpaksa, individu tersebut akan mengikuti hasil keputusan itu.

Tolley (2013) mengatakan konsep konformitas adalah suatu bagian terbesar dalam hidup remaja dimana mereka mencoba mencari teman, dan terus berlanjut sampai dewasa. Tolley (2013) menambahkan yang menjadi faktor penyebab terjadinya konformitas adalah unsur-unsur campuran yang berbeda. Diantaranya keingintahuan, persepsi, komunitas dimana mereka tinggal, dll. Keingintahuan adalah salah satu unsur yang dapat membawa remaja ke dalam situasi dengan pilihan dimana mereka mungkin melakukan perilaku konformitas yang negatif. Persepsi remaja dari lingkungan mereka tinggal dapat sangat mempengaruhi dengan apa yang mereka lakukan, dan yang lebih penting bahwa apa yang mungkin benar-benar terjadi di lingkungan mereka (Duan, Chou, Andreeva, and Pents, 2008). Persepsi berpengaruh langsung dengan lingkungan. Jika siswa melihat sekolah sebagai tempat yang positif, mereka akan mengikuti atau bergaul dengan hal-hal yang baik. Siswa memiliki kebutuhan yang kuat untuk dapat diterima di lingkungan mereka yang mana mempengaruhi apa yang mereka pilih untuk melakukan sesuatu agar merasa diterima dengan lingkungan mereka (Tolley, 2013). Faktor ketiga adalah komunitas lokal dan lingkungan memiliki aturan lokal yang mana harus diikuti oleh remaja yang ingin masuk ke dalam suatu komunitas tertentu itu. Bisa merupakan komunitas kecil seperti beberapa teman, atau besar seperti komunitas sekolah atau komunitas lokal. Keingintahuan, persepsi dan komunitas mempengaruhi sejumlah perilaku konformitas pada remaja yang akan mereka lalui dalam masa perkembangan mereka.

Konformitas diklasifikasikan menjadi dua yaitu rational conformity dan irrational conformity. Rational conformity adalah perilaku yang terjadi melaui proses berfikir, pertimbangan dan alasan. Hal itu terjadi sebagai hasil dari pengaruh tekanan oleh perilaku atau sikap yang meliputi abidiance, compliance, dan obedience. Irrational conformity atau kumpulan perilaku adalah perilaku seseorang ketika mereka melakukannya karena intuisi and aktifitas insting dan dipengaruhi oleh perilaku atau sikap dari objek tertentu. (Song, 2010). 
Konformitas dibagi dalam 3 tingkat diantaranya Hurlock (1999) membagi konformitas yang dilakukan remaja terhadap teman sebaya ke dalam tiga tingkatan, yakni sebagai berikut. (1) Developmentally Appropiate Conformity. Merupakan bentuk penyesuaian yang dilakukan oleh remaja terhadap standar atau aturan-aturan yang telah ditetapkan oleh kelompok tanpa membuat dirinya kehilangan identitas. Remaja dengan tingkat konformitas yang tepat tidak mengorbankan individualitasnya dalam melakukan tindakan penyesuaian; (2) Lack of Conformity. Merupakan bentuk ketidak mampuan remaja dalam melakukan penyesuaian baik tingkah laku atau pendapat terhadap standar atau aturan yang telah ditetapkan oleh kelompok, sehingga rentan mengakibatkan penolakan sosial dari kelompok tersebut; (3) Over Conformity. Merupakan konformitas yang berlebihan, yaitu bentuk penyesuaian baik berupa tingkah laku, pemikiran ataupun pendapat terhadap aturan-aturan yang telah ditetapkan oleh kelompok secara berlebihan sehingga menyebabkan remaja kehilangan identitas. Remaja yang memiliki konformitas yang berlebihan cenderung merasa cemas ketika bersikap yang tidak sesuai dengan harapan kelompok, dan pada akhirnya membuat remaja sangat ketergantungan terhadap teman kelompoknya.

Adanya norma yang ada di dalam suatu kelompok mempengaruhi terbentuknya konformitas yang mana dipatuhi oleh anggota kelompok tersebut. Norma merupakan pedoman-pedoman untuk mengatur pengalaman dan tingkah laku yang patut dilakukan oleh anggota kelompok apabila terjadi sesuatu yang bersangkut-paut dengan kehidupan kelompok tersebut. Norma kelompok memberikan pedoman mengenai tingkah laku mana dan sampai batas mana perilaku seseorang masih dapat diterima oleh suatu kelompok (Gerungan, 2010).

Di beberapa budaya konformitas merupakan hal yang wajar. Individu melakukan sesuatu karena meniru orang lain agar dapat diterima dikelompok sering terjadi di beberapa budaya. Penelitian mengenai konformitas ditinjau dari berbagai budaya dilakukan oleh Zhang dan Thomas (1994) meneliti mengenai teori modern yang menjelaskan perilaku konformitas untuk menemukan tiga pola dari budaya yang berbeda. Subjek penelitiannya adalah mahasiswa dari China, Taiwan, dan U.S. Hasil dari penelitian ini adalah ada perbedaan konformitas di China antara laki-laki dan perempuan, konformitas pada perempuan diluar dugaan lebih tinggi dari pada laki-laki. Tetapi di Taiwan tidak ada korelasi yang signifikan konformitas terhadap perilaku akademik. Sedang. 
Sebagai pembanding dengan model hipotesis, partisipan di Cina dan Taiwan tidak ada efek dari status sosial ekonomi keluarga, kepercayaan orang tua, dan kepercayaan partisipan terhadap perilaku konformitas. Hal yang sama terjadi pada partisipan U.S konformitas memiliki hubungan yang negatif dengan status.

Penelitian untuk mengembangkan instrumen mengenai konformitas dilakukan oleh Santor, Messervey, dan Kusumakar (2001) dimana mereka mengembangkan pengukuran pendek yang valid dari tekanan teman sebaya, konformitas teman sebaya, dan popularitas dengan jumlah sampel sebanyak 148 remaja laki-laki dan perempuan. Hasil penelitian menunjukkan bahwa semua pengukuran dari tekanan teman sebaya, konformitas teman sebaya, dan popularitas berkorelasi satu sama lain, tekanan teman sebaya dan konformitas teman sebaya menjadi prediktor terkuat dai resiko perilaku dari pada pengukuran popularitas, konformitas umum, dan disporia. Alat ukur yang digunakan dalam penelitian Santor, Messervey, \& Kusumakar (2001) dengan mengembangkan alat ukr dari penelitian sebelumnya oleh Brendt (1979) dan Brown Clasen, \& Ficher (1986). Berdasarkan kajian di atas penulis ingin meneliti mengenai konformitas teman sebaya dalam perspektif multicultural untuk memahami konformitas pada perspektif multikultural. Multikultural disini melihat perbedaan konformitas teman sebaya antara siswa laki-laki dan siswa perempuan.

\section{METODE}

Pendekatan penelitian menggunakan pendekatan kuantitatif dengan jenis penelitian menggunakan tipe cross sectional survey. Dimana penelitian ini hanya mengetahui konformitas berdasarkan perspektif multibudaya. Partisipan dalam penelitian ini adalah siswa Sekolah Menengah Atas (SMA) di Bandar Lampung yang ditentukan dengan teknik pengambilan sampel purposive sample sehingga didapat jumlah partisipan sebanyaka 76 siswa yang terdiri dari 32 orang partisipan laki-laki dan 44 orang partisipan perempuan. Rata-rata usia partisipan dalam penelitian ini adalah 15-17 tahun dimana siswa termasuk pada tahap perkembangan remaja.

Instrumen yang digunakan dalam studi ini adalah skala konformitas teman sebaya. Untuk memenuhi syarat agar suatu instrumen dikatakan baik maka dilakukan uji validitas dan reliabilitas terhadap instrumen konformitas teman sebaya. Validitas yang digunakan adalah validitas isi dimana penilaian 
dilakukan oleh ahli untuk memberikan profesional judgement. Setelah mendapat expert judgment, instrumen diujicobakan lalu dihitung korelasinya untuk melihat apakah item dari instrumen berkorelasi dengan aitem total dengan menggunakan analisis korelasi Spearmen-Brown. Sedangkan reliabilitasnya dihitung dengan analisis split-half dengan bantuan SPSS 17 didapat skor untuk reliabilitas dari instrumen konformitas teman sebaya sebesar 0,87 yang menunjukkan bahwa instrumen memiliki reliabilitas yang baik/tinggi.

Pengukuran konformitas teman sebaya berdasarkan perspektif multibudaya dalam hal ini dilihat dari jenis kelamin maka, kelompok partisipan dibagi menjadi dua yaitu kelompok siswa laki-laki dan kelompok siswa perempuan. Skala konformitas teman sebaya dibagikan kepada dua kelompok partisipan, dalam proses pengisian skala siswa didampingi oleh peneliti agar data yang ingin di ambil sesuai dengan apa yang diharapkan. Skala terdiri dari identitas yang harus diisi yang berisi informasi umum.

Skala yang telah diisi oleh siswa lalu hasil data diolah dengan membandingkan mean kedua kelompok tersebut menggunakan analisi uji beda Man U Withney dengan bantuan program SPSS 17. Uji beda Man U Whitney digunakan untuk melihat signifikansi perbedaan antara dua populasi, dengan menggunakan sampel random yang ditarik dari populsi yang sama.

\section{HASIL PENELITIAN DAN PEMBAHASAN}

Hasil uji statistik yang telah dilakukan untuk melihat perbedaan konformitas teman sebaya berdasarkan demografi status sosial ekonomi mendapatkan data bahwa rata-rata skor konformitas teman sebaya untuk kelompok 1 (siswa lakilaki) sebesar 38,55 sedangkan rata-rata untuk kelompok 2 (siswa perempuan) 38,47. Berdasarkan uji beda mann whitney $U$ diperoleh hasil sebesar 702,500 dengan nilai probabilitas signifikansi sebesar 0,987. Karena pobabilitas 0,987 > 0,05 maka tidak ada perbedaan antara konformitas teman sebaya kelompok siswa laki-laki dengan konformitas teman sebaya kelompok siswa perempuan. Artinya tidak ada perbedaan konformitas berdasarkan perspektif multibudaya, baik siswa laki-laki maupun siswa perempuan keduanya memiliki konformitas teman sebaya yang sama. Hasil uji statistik dapat dilihat pada Tabel 1. 
Tabel 1. Uji Beda Komformitas Teman Sebaya Perspektif Multibudaya.

\begin{tabular}{|c|c|c|c|c|}
\hline & JenisKelamin & $\mathrm{N}$ & Mean Rank & Sum of Ranks \\
\hline \multirow[t]{3}{*}{ KONFORMITAS } & 1 & 32 & 38.55 & 1233.50 \\
\hline & 2 & 44 & 38.47 & 1692.50 \\
\hline & Total & 76 & & \\
\hline \multicolumn{5}{|c|}{ Test Statistics ${ }^{\mathrm{a}}$} \\
\hline & & \multicolumn{3}{|c|}{ KONFORMITAS } \\
\hline Mann-Whitney U & & \multicolumn{3}{|c|}{702.500} \\
\hline Wilcoxon W & & \multicolumn{3}{|c|}{1692.500} \\
\hline $\mathrm{Z}$ & & \multicolumn{3}{|c|}{-.016} \\
\hline Asymp. Sig. (2-tai & & \multicolumn{3}{|c|}{.987} \\
\hline
\end{tabular}

a. Grouping Variable: Jenis Kelamin

Hasil atau data penelitian di atas menunjukkan bahwa tidak ada perbedaaan konformitas antara kelompok siswa laki-laki dan kelompok siswa peremuan. Hasil penelitian ini berbeda dengan hasil penelitian sebelumnya yang dilakukan oleh Zhang dan Thomas (1994) dalam menguji teori modern yang menjelaskan perilaku konformitas untuk menemukan tiga pola dari budaya yang berbeda. Subjek penelitiannya adalah mahasiswa dari China, Taiwan, dan U.S. Hasil dari penelitian ini adalah ada perbedaan konformitas di China antara laki-laki dan perempuan, konformitas pada perempuan diluar dugaan lebih tinggi dari pada laki-laki. Tetapi di Taiwan tidak ada korelasi yang signifikan konformitas terhadap perilaku akademik. Sedangkan sebagai pembanding dengan model hipotesis, partisipan di Cina dan Taiwan tidak ada efek dari status sosial ekonomi keluarga, kepercayaan orang tua, dan kepercayaan partisipan terhadap perilaku konformitas. Hal yang sama terjadi pada partisipan U.S konformitas memiliki hubungan yang negatif dengan status sosial ekonomi. Artinya di Cina, Taiwan maupun U.S konformitas teman sebaya berbeda berdasarkan kelompok jenis kelamin. Perempuan cendrung lebih konform terhadap teman sebaya daripada laki-laki.

Tolley (2013) mengatakan konsep konformitas adalah suatu bagian terbesar dalam hidup remaja dimana mereka mencoba mencari teman, dan terus berlanjut sampai dewasa. Tolley (2013) menambahkan yang menjadi faktor penyebab terjadinya konformitas adalah unsur-unsur campuran yang berbeda. Diantaranya keingintahuan, persepsi, komunitas dimana mereka tinggal, dll. Keingintahuan adalah salah satu unsur yang dapat membawa remaja ke dalam 
situasi dengan pilihan dimana mereka mungkin melakukan perilaku konformitas yang negatif. Persepsi remaja dari lingkungan mereka tinggal dapat sangat mempengaruhi dengan apa yang mereka lakukan, dan yang lebih penting bahwa apa yang mungkin benar-benar terjadi di lingkungan mereka (Duan, Chou, Andreeva, and Pents, 2008).

Persepsi berpengaruh langsung dengan lingkungan. Jika siswa melihat sekolah sebagai tempat yang positif, mereka akan mengikuti atau bergaul dengan halhal yang baik. Siswa memiliki kebutuhan yang kuat untuk dapat diterima di lingkungan mereka yang mana mempengaruhi apa yang mereka pilih untuk melakukan sesuatu agar merasa diterima dengan lingkungan mereka (Tolley, 2013). Faktor ketiga adalah komunitas lokal dan lingkungan memiliki aturan lokal yang mana harus diikuti oleh remaja yang ingin masuk ke dalam suatu komunitas tertentu itu. Bisa merupakan komunitas kecil seperti beberapa teman, atau besar seperti komunitas sekolah atau komunitas lokal. Keingintahuan, persepsi dan komunitas mempengaruhi sejumlah perilaku konformitas pada remaja yang akan mereka lalui dalam masa perkembangan mereka. Teori tersebut memperkuat hasil penelitian ini yang menekankan faktor terjadinya konformitas tidak dipengaruhi oleh perbedaan jenis kelamin.

Persepsi siswa terhadap konformitas diteliti oleh Killen, Crustal dan Watanabe (2002) subjek penelitian berjumlah 1057 siswa yang dibagi berdasarkan jenis kelamin, siswa kelas empat, tujuh dan kelas sepuluh dari dua kota U.S dan Jepang. 513 siswa Jepang dan 544 siswa U.S. Persepsi dari konformitas dilihat dari pengaruh budaya, jenis kelamin, usia. Hasil penelitian ditinjau dari pengaruh budaya siswa menganggap persepsi terhadap konformitas dipengaruhi oleh perbedaan budaya.

Secara kolektif, karakter dari pengelompokkan, konformitas dan kesetiaan terhadap tanggung jawab merupakan sifat budaya Jepang (Gudykunst, Yoon, \& Tsukasa, 1987; Matsumoto, 1990; Peak, 1989; Triandis, 1995). Artinya konformitas dipengaruhi oleh kebudayaan masing-masing. Dimana di Jepang konformitas, kesetiaan, tanggung jawab merupakan sifat budaya masyarakat Jepang. Faktor kedua adalah jenis kelamin. Jenis kelamin merupakan prediksi terkuat dari persepsi terhadap konformitas. Killen, Crustal dan Watanabe (2002) menemukan bahwa harapan laki-laki lebih konformitas dari teman sebaya daripada perempuan. Hasil penelitian ini berdasarkan pnelitian sebelumnya yang melaporkan tingkat konformitas sejumlah perempuan dan laki-laki (Boehnke, Silbereisen, Einsenberg, \& Reykowaki, 1989; Werrbach, Grotevant, 
\& Cooper, 1990). Hal ini berdasarkan asumsi bahwa perempuan lebih terbuka terhadap pengalaman mereka dari pada laki-laki. Dapat ditarik kesimpulan pada penelitian yang dilakukan oleh Killen, Crustal dan Watanabe (2002) bahwa persepsi siswa terhadap konformitas dipengaruhi oleh tiga hal yaitu, usia, jenis kelamin, dan budaya. Persepsi terhadap konformitas artinya adalah bagaimana siswa menggambarkan apa itu konformitas, dengan persepsi yang dimiliki siswa akan menentukan perilaku konformitas yang mereka lakukan.

Penelitian lain membahas mengenai konformitas dari tahap usia yang lain yaitu usia dewasa dan anak-anak. Peneilitian psikologi sosial dengan populasi dewasa mengindikasikan bahwa konformitas individu secara seksama, keanggotaan atau tujuan konsep diri, dan pemenuhan tujuan merupakan penghargaan terhadap diri sendiri (Cialdini \& Goldstein, 2004). Individu mungkin mengadopsi perilaku spesifik dan sikap untuk emmelihara konsep diri yag positif. Khususnya, konsep diri adalah secara parsial menentukan kelompom dengan idektitas individu; oleh karena itu konformitas untuk perilaku seperti menolong kelompo untuk menguatkan penilaian yang dimiliki individu (Cialdini \& Goldstein 2004).

Penelitian dengan populasi anak-anak menunjukkan bahwa konformitas perilaku pada kelompok teman sebaya untuk tujuan penguatan poitif. Khususnya anak-anak lebih menyerupai untuk menampilkan perilaku penguatan positif dari teman sebayanya dan tidak menyerupai untuk menampilkan perilaku menghukum dari kelompok mereka (Brown, Clasen, \& Ficher, 1986). Penelitian lain mengindikasikan bahwa anak-anak terutama menyerupai konformitas pada perilaku negatif dari teman sebayanya ketika teman sebaya mereka ada pada status sosial yan tinggi (Cohen \& Prinstein, 2006; Shi \& Xie 2012). Artinya anak-anak akan melakukan konformitas teman sebaya dengan perilaku negatif terhadap teman sebaya mereka dengan status sosial yang tinggi.

\section{SIMPULAN}

Berdasarkan hasil dan diskusi di atas maka simpulan dalam penelitian ini adalah tidak ada perbedaan konformitas antara kelompok siswa laki-laki dan kelompok siswa perempuan. Konformitas sering terjadi di usia remaja, mengingat pada tahap perkembangan remaja cendrung berkelompok. Peran sekolah sangat diperlukan dalam mengontrol perilku remaja dalam hal ini perilaku 
konformitas. Konformitas dapat dikembangkan ke arah yang positif, baik itu melalui pembelajaran, kegiatan di dalam maupun di luar kelas.

\section{REFERENSI}

Boehnke, K., Silbereisen, R. K., Eisenberg, N., \& Reykowski, J. (1989). Developmental patterns of prosocial motivation: A cross-national study. Journal Of Cross-Cultural Psychology, 20, 219-243.

Bentz, J. L., \& Fuchs, L. S. (1996). Improving peers' helping behavior to students with learning disabilities during mathematics peer tutoring. Learning Disability Quarterly, 19(4), 202-215.

Brendt, T. J. (1979). Developmental changes in comformity to peers and parents. Develop, Psychology, 15, 606-616.

Brown, B. B., Claesen, D. R., \& Eicher, S. A. (1986). Perceptions of peer pressure, peer conformity dispositions, and self-reported behavior among adolescents. Developmental psychology, 22(4), 521-530.

Bryan, T., Pearl, R., \& Fallon, P. (1989). Conformity to peer pressure by students with learning disanilities : a replication. Journal of learning Disabilities, 22(7), 458-460.

Cialdini, R. B., \& Goldstein, N. J. (2004) Social influences: Compiliance and comformity. Annual Review of Psychology, 55, 591-621.

Cohen, G. L., \& Prinstein, M. J. (2006). Peer contagion of aggression and health risk behavior among adolescent males: an experimental investigation of effects on public conduct and private attitudes. Child Development, 77(4), 967-983.

Dejnozken, E. L., \& Kopel, D. E. (1976). American educator encyclopedy. London: Greenwood Press.

Duan, L., Chou, C., Andreeva, V., \& Pentz, M. (2009). Trajectories of peer social influences as long-term predictors of drug use from early through late adolescence. Journal of Youth \& Adolescence, 38(3), 454-465.

Gerungan, W. A. (2010). Psikologi Sosial. Refika Aditama: Bandung.

Gudykunst, W. B., Yoon, Y. C., \& Nishida, T. (1987). The influence of individualism-collectivism on perceptions of communication in ingroup and outgroup relationships. Communications Monographs, 54(3), 295306. 
Hurlock, E. (1999). Psikologi Perkembangan Suatu Pendekatan Sepanjang Rentang Kehidupan. Jakarta: Erlangga.

Killen, M., Crystal, D. S., \& Watanabe, H. (2002). Japanese and American children's evaluating of peer exclusion, tolerance of differeces, and prescriptions for conformity. Child Development, 73(6), 1788-1802.

Lease, A. M., \& Axelrod, J. L. (2001). Position in the peer group's perceived organizational structue : relation to social status and friendship. Journal of Early Adolescence, 21(4), 377-404.

Lefcourt, H. M. (1966). Internal versus external control of reinforcement: A review. Psychology Bulletin. 65, 206-202

Lopez, M. P. S., Flores, I. C., Dresch, V., \& Garcia, M. A. (2009). Conformity to feminime gender norms in the spanish popuation. Social Behaviour and Personality, 37 (9), 1171-1186.

Matsumoto, D. (1990). Cultural similarities and differences in display rules. Motivation and Emotion, 14, 195-214.

Mőnks, F. J., Knoers, A. M. P., Haditono, S. R. (2004). Psikologi Perkembangan. Yogyakarta: Gadjah Mada University Press.

Myers, D. G. (2010). Social Psychology (10th ed.). New York: Mc Graw-Hill.

Nesdale, D., Mass, A., Kisner, J., Durkin, K., Griffths, J., \& Ekberg, A. (2007). Effect of peer group rejection, group membership, and group norms, on children's outgroup prejudice. International Journal of Behavioral Development, 31(5), 526-535.

Peak, L. (1989). Learning to become part of the group: The Japanese child's transition to preschool life. Journal of Japanese Studies, 1, 93-123.

Santor, D. A., Messervey, D., \& Kusumakar, V. (2000). Measuring peer pressure, popularity, and conformity in adolescent boys and girls: Predicting school performance, sexual attitudes, and substance abuse. Journal of youth and adolescence, 29(2), 163-182.

Santrock, J. W. (2002). Life-Span Development (Perkembangan Masa Hidup). Jakarta: Erlangga.

Shi, B., \& Xie, H. (2012). Socialization of physical and social aggression in early adolescents' peer groups: High-status peers, individual status, and gender. Social Development, 21(1), 170-194.

Song, G., Ma, Q., Wu, F., \& Li, L. (2012). The psychological explanation of conformity. Social Behavior and Personality: An International Journal, 40(8), 1365. 
Triandis, H. (1995). Individualism and collectivism. Boulder, CO: Westview Press.

Tolley, R. A. (2013). Conformity: drug and alcohol abuse within adolescent communities. USA: Lincoln Memorial University

Zhang, J., \& Thomas, D. L. (1994). Modernization theory revisited: A crosscultural study of adolescent conformity to significant others in mainland China, Taiwan, and the USA. Adolescence, 29(116), 885. 